\title{
Responses of salt-stressed citrus plants to foliar-applied proline
}

\section{Mehmet Ali Demiral a,*, Juan Carlos Melgar b, Beatriz Contreras c, Ayako Kusakabe d, Murat Uygun e, Seçil Küçük Kaya a}

\author{
a Adnan Menderes University, Faculty of Agriculture, Department of Soil Science and Plant Nutrition, Aydın, Turkey \\ b Clemson University, Department of Plant and Environmental Sciences, Clemson, South Carolina, USA \\ c Texas A\&M University-Kingsville, Citrus Center, Weslaco, Texas, USA \\ $\mathrm{d}$ The University of Arizona, Department of Entomology, Tucson, Arizona, USA \\ e Adnan Menderes University, Faculty of Science, Department of Chemistry, Aydın, Turkey
}

\section{Article Info}

Received : 09.03.2018

Accepted : 01.11.2019

\begin{abstract}
In this study, one-year old grapefruit trees grafted onto sour Orange (SO) and $\mathrm{C} 22$ rootstocks were exposed to $\mathrm{NaCl}$-induced salinity (approx. $6 \mathrm{dS} \mathrm{m}^{-1}$ ) in pot culture for two months under greenhouse conditions. The experiment was laid out in a randomized block design with eight replicates. The trees were irrigated with saline solution containing $0.1 \%$ liquid fertilizer "Miracle-Gro Liqua Feed 9-4-9" $\left(\mathrm{N}-\mathrm{P}_{2} \mathrm{O}_{5}-\mathrm{K}_{2} \mathrm{O}\right)$ enriched with micronutrients. The experimental treatments consisted of three levels (4 mM, $8 \mathrm{mM}, 12 \mathrm{mM})$ of foliar applied proline along with control application. Distilled water served as the control. During the experiment the seedlings were sprayed totally five times with ten days intervals. At the end of the treatment physiologically mature leaves, free of damage or defects, were sampled. Dried and ground leaf samples were used for chemical ( $\mathrm{Na}$ and $\mathrm{Cl}$ ) and biochemical (DPPH scavenging activity, reducing power, total phenolic content, proline) analysis. Spesific leaf area, leaf water relations and leaf gas exchange of the plants were also determined. Foliar PRO application decreased $\mathrm{Na}$ and $\mathrm{Cl}$ concentrations of the leaves, and improved spesific leaf area in the final dose. Water leaf relations, photosynthetic activity and biochemical parameters were affected positively even though some differences were determined between the cultivars.
\end{abstract}

Keywords: Salinity, proline, $\mathrm{NaCl}, \mathrm{C} 22$, SO.

(c) 2020 Federation of Eurasian Soil Science Societies. All rights reserved

\section{Introduction}

Citrus is one of the important horticultural crops worldwide and is relatively salt sensitive. In many of its growing regions, such as Texas in the US and Turkey in the Mediterranean Basin, drought and salinity are the most limiting abiotic factors for the production.

Compatible solutes, such as proline (PRO) is known to play a role in the process of osmotic adjustment in many crops and to accumulate under conditions of environmental stresses (Rhodes and Hanson, 1993). Their main role is probably to insulate plant cells against the ravages of salt by preserving the osmotic balance, by stabilizing the structure of key proteins such as Rubisco, by protecting the photosynthetic apparatus and by functioning as oxygen radical scavengers. In general, many plant species accumulate these organic osmolytes to overcome abiotic stress factors such as salinity and drought. Therefore, exogenous application of these compounds has been suggested as an alternative/additional approach to genetic engineering to improve crop productivity under stress conditions (Itai and Paleg, 1982). In recent years, foliar application of PRO has been proven useful to reduce the negative effects of abiotic stress factors in different perennial plants. The purpose of this study was to provide additional information on foliar application of PRO and its ability to counteract salt inhibitory effects in citrus.

\footnotetext{
${ }^{*}$ Corresponding author.

Adnan Menderes University, Faculty of Agriculture, Department of Soil Science and Plant Nutrition, Aydın, Turkey

Tel.: +902567727022

E-mail address: mademiral@yahoo.com

e-ISSN: 2147-4249 DOI: $10.18393 /$ ejss. 647020
} 


\section{Material and Methods}

The research was carried out in a greenhouse at Texas A\&M University-Kingsville Citrus Center, located in Weslaco, TX (USA) during July 11, 2013 -September 21, 2013. Approximately 1 year-old Sour Orange (SO) and C22 cultivars' seedlings were grown in $10 \mathrm{~cm} \times 10 \mathrm{~cm} \times 36 \mathrm{~cm}$ tall pots.

After planting the seedlings were started to irrigate with an amount of water accounting for a leaching factor of $50-55 \%$ and fertilized with $0.1 \%$ liquid fertilizer "Miracle-Gro Liqua Feed 9-4-9" $\left(\mathrm{N}-\mathrm{P}_{2} \mathrm{O}_{5}-\mathrm{K}_{2} \mathrm{O}\right)$ enriched with micronutrients. Average water applied per pot was about $1000 \mathrm{ml}$ during the experiment.

In order to create salt stress on plants the seedlings were exposed to NaCl-induced salinity (approx. $6 \mathrm{dSm}^{-1}$ ) during the experiment. Salinity level was adjusted by the addition of appropriate amounts of $\mathrm{NaCl}$ to the applied nutrient solution and increased gradually in order to prevent any possible shock effect of salinity on experimental plants. Average EC of leachate was measured about $5.23 \mathrm{dS} \mathrm{m}^{-1}$ during the experiment.

Experimental treatments consisted of 3 levels ( $4 \mathrm{mM}, 8 \mathrm{mM}, 12 \mathrm{mM})$ of foliar-applied PRO. Distilled water served as the control application. Twenty days after the first salt solution application to the pots the seedlings were sprayed with PRO solutions for 5 times with 10 days intervals. Applications were performed between $6.30 \mathrm{am}-7.30 \mathrm{am}$ and approximately $500 \mathrm{ml}$ of PRO solution was used for each replication (8 plants in total).

At the end of the experiment physiologically mature leaves, free of damage or defects, were sampled. In order to eliminate surface contamination, leaves were carefully washed with tap water and rinsed 2 times with deionized water. For chemical and biochemical analysis, the samples were placed in paper bags and dried in a forced-air oven at $70^{\circ} \mathrm{C}$ for 72 hours. The dried leaf samples were then ground in a stainless steel mill (IKA A 11 Basic, Staufen, Germany).

\section{Chemical analysis}

For $\mathrm{Na}$ determination the ground leaf samples were wet digested in a mixture of nitric/perchloric acid $\left(\mathrm{HNO}_{3} / \mathrm{HClO}_{4}\right)(4 / 1, \mathrm{v} / \mathrm{v})$ solution. Sodium contents in the digest were determined using flame photometer (Jenway PFP7, Staffordshire, UK) (Westerman, 1990). Chloride was extracted from $0.1 \mathrm{~g}$ of ground sample by shaking the mixture with $10 \mathrm{ml}$ of deionized water for $2 \mathrm{~h}$. Chloride concentrations of the extracts were measured by chloridometer (Jenway PCLM3, Staffordshire, UK) (Brown and Jackson, 1955).

\section{Physiological analysis}

Leaf dry matter percentage (DMP) was calculated based on leaf fresh weight (FW) and dry weight (obtained after $48 \mathrm{~h}$ at $\left.+80^{\circ} \mathrm{C}, \mathrm{DW}\right)$. DMP was calculated by using (DMP $=100 \times(\mathrm{FW}-\mathrm{DW}) /(\mathrm{FW})$ equation.

Spesific leaf area (SLA) was determined by using total leaf area and leaf dry weight values measured at the end of the experiment. SLA was calculated by using (leaf area $\left(\mathrm{cm}^{2}\right) /$ leaf DW (g)) equation.

\section{Biochemical analysis}

Proline (PRO) analysis was performed on dried leaf samples according to Bates et al. (1973). In order to determine total phenolic contents (TPC), reducing power (RP) and DPPH radical scavenging activity a plant extract was prepared. Distilled water were employed for the preparation of plant extracts. In brief, $0.25 \mathrm{~g}$ of ground leaf was mixed with $5 \mathrm{~mL}$ of water and the mixture was shaken for $2 \mathrm{~h}$ in a shaker (Heidolph Promax 2020, Schwabach, Germany). The filtrate was then used for analysis immediately. Total phenolic content (TPC) of the extracts was assayed according to the Folin-Ciocalteu method (Singleton et al., 1999). Reducing power (RP) of the extracts was measured according to the method of Oyaizu (Oyaizu, 1986). Radical scavenging activity of the plant extracts against the DPPH radical was determined spectrophotometrically according to Brand-Williams et al. (1995).

\section{Leaf water relations}

During the experiment leaf water status were determined 3 times, July 30, 2013 (4 leaves of each PRO application); August 21, 2013 (4 leaves of each PRO application); and September 20, 2013 (5 leaves of each PRO application). For this purpose a Scholander-type pressure chamber (PMS Instrument Co., Albany, OR) (Scholander et al., 1965) was used. The leaves were previously introduced in plastic bags covered with duct tape that avoided light penetration, minimized transpiration and equilibrated leaf water potential. Measurements were taken at least $2 \mathrm{~h}$ after leaves were covered, normally starting at 13:00 $\mathrm{h}$. In order to determine the osmotic potential of the leaves an osmometer (Wescor Vapro 5600- Wescor Inc. Logan, UT) was used.

\section{Chlorophyll fluorescence system and leaf gas exchange}

Chlorophyll fluorescence measurements were performed on intact leaves with a portable Opti-Sciences OS1p fluorometer on 4 plants per PRO application totally 32 plants in August 21, 2013 between 16 pm and 
$16.30 \mathrm{pm}$. Leaf $\mathrm{CO}_{2}$ gas exchange measurements were performed on 6 plants per PRO application totally 48 plants in September 20, 2013 between 10 am and 12 am. For this purpose Licor 6400 photosynthesis system was used.

\section{Experimental design and statistical analysis}

The experiment was laid out in a randomized block design with 8 replicates and 1 plant per pot. Regression analyses were carried out according to Little and Hills (1978) for the investigation of the relationship between PRO and the experimental data.

\section{Results}

Sodium concentrations of C22 and SO leaves increased up to $8 \mathrm{mM}$ and $4 \mathrm{mM}$ respectively, and then decreased. In terms of leaf $\mathrm{Cl}$ concentrations; increasing PRO doses decreased leaf $\mathrm{Cl}$ concentrations of the cultivars linearly (Table 1 ).

Leaves' DMP of the cultivars increased up to $8 \mathrm{mM}$ PRO application then decreased (Table 2). Specific leaf area and leaf PRO content of the cultivars showed a fluctuation with the increasing PRO application doses (Table 2 and Table 3).

RP increased with increasing PRO application doses (Table 3). TPC content increased up to 8 mM PRO application dose and then decreased in C22. On the other hand a fluctation was observed in SO (Table 4). Increasing foliar PRO doses decreased leaf DPPH scavenging activity of SO up to $8 \mathrm{mM}$ PRO and then increased. A fluctation was observed in C22 (Table 4). Compared to control application; increasing PRO application doses decreased pressure potential of the C22 leaves at first and then increased it in the $8 \mathrm{mM}$ and $12 \mathrm{mM}$ PRO application doses. Increasing PRO application doses increased pressure potential of SO leaves up to $8 \mathrm{mM}$ PRO and then decreased in $12 \mathrm{mM}$ PRO (Table 5).

Compared to control application; osmotic potential of the C22 leaves increased initially and then decreased after $8 \mathrm{mM}$ and $12 \mathrm{mM}$ PRO applications. Osmotic potential of the SO leaves increased constantly (Table 5). Increasing foliar applied PRO increased the leaves' water potential of the cultivars up to $8 \mathrm{mM}$. In the highest PRO application dose $(12 \mathrm{mM})$ leaf water potentials of the cultivars stayed stable in C22 and decreased in the SO (Table 6).

In terms of photosynthesis, stomatal conductance and leaf transpiration rate; the cultivars showed similar response to the increasing PRO application doses. All the parameters given above decreased with the increasing PRO application up to $8 \mathrm{mM}$ then increased. On the other hand; increased PRO doses affected water use efficiency (WUE) of the cultivars in different ways. WUE of the cultivar C22 increased in the first application dose $(4 \mathrm{mM})$ and then decreased. However, WUE of the cultivar SO stayed stable up to the last application dose ( $12 \mathrm{mM}$ ) and then increased. Ci/Ca of the cultivar C22 increased with the increase in PRO doses, while Ci/Ca of the cultivar SO was decreased (Tables 6-8).

\section{Discussion}

Foliar application of PRO offers a valuable tool for studying mechanisms of salt tolerance. One of these mechanisms depends on the capacity for osmotic adjustment which allows growth to continue under saline conditions. It is generally accepted that under salt stress, this process is mainly achieved by uptake and accumulation of inorganic ions, mainly $\mathrm{Na}^{+}$and $\mathrm{Cl}^{-}$and partly by synthesis and accumulation of organic compatible compounds (Demiral et al., 2011; Flowers et al., 1977). Increasing PRO application doses decreased $\mathrm{Na}$ concentration of the leaves in the final doses. Chloride concentrations of the leaves decreased steadily with the increasing PRO application doses (Table 1). It might be concluded that exposure of the plants to saline nutrient solution increased the levels of $\mathrm{Na}$ in the leaves. As reported, there is a relationship between the PRO content and the osmotic adjustment in plants under salt stress (Rhodes and Hanson, 1993). Depicted in Table 1, Na concentration of the cultivars' leaves was decreased in the highest PRO application dose. On the other hand PRO did not affect $\mathrm{Cl}$ accumulation of the leaves. This process might also be related to decrease uptake capacity of the plants' roots. According to Lin and Kao (2001) exogenous application of PRO markedly inhibited root growth of rice. Hence decreasing $\mathrm{Na}$ and $\mathrm{Cl}$ concentrations of the leaves under increasing PRO applications might be related to decreasing uptake potential of the roots.

The DMP and SLA of the cultivars' leaves increased up to $8 \mathrm{mM}$ application dose and then decreased (Table 2). This might be accomplished by adjusting the osmotic potentials of the cells in the leaves through the organic and/or inorganic solutes. According to Tester and Davenport (2003), the exposure of plants to salinity commonly results in a water deficit in plant cells, and maintaining osmotic homeostatis requires an adjustment in osmotica, either by the uptake of soil solutes or by the synthesis of metabolically compatible compounds. Probably changes in the Na concentrations of the cultivars' leaves support this tendency (Table 1). 


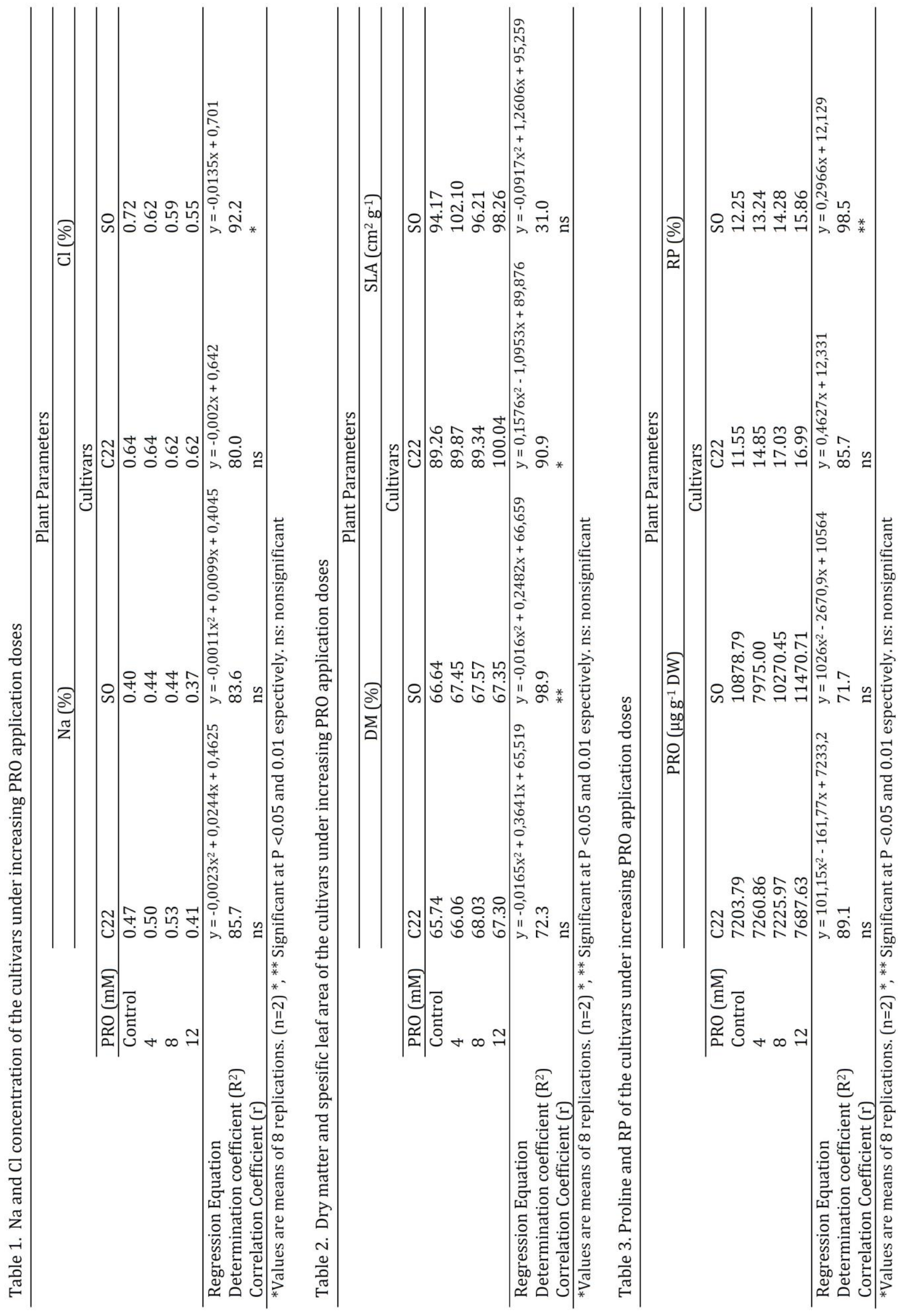




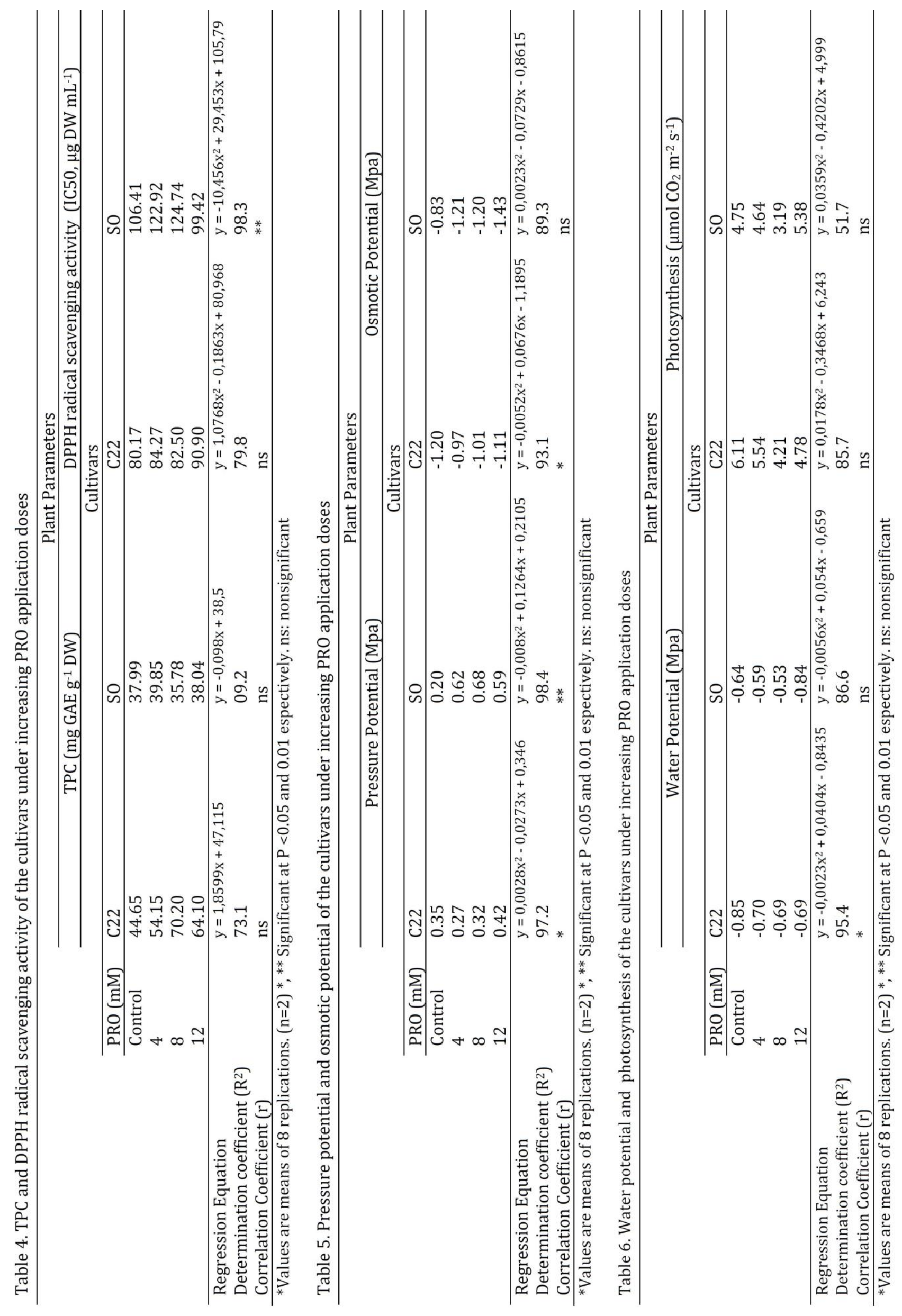




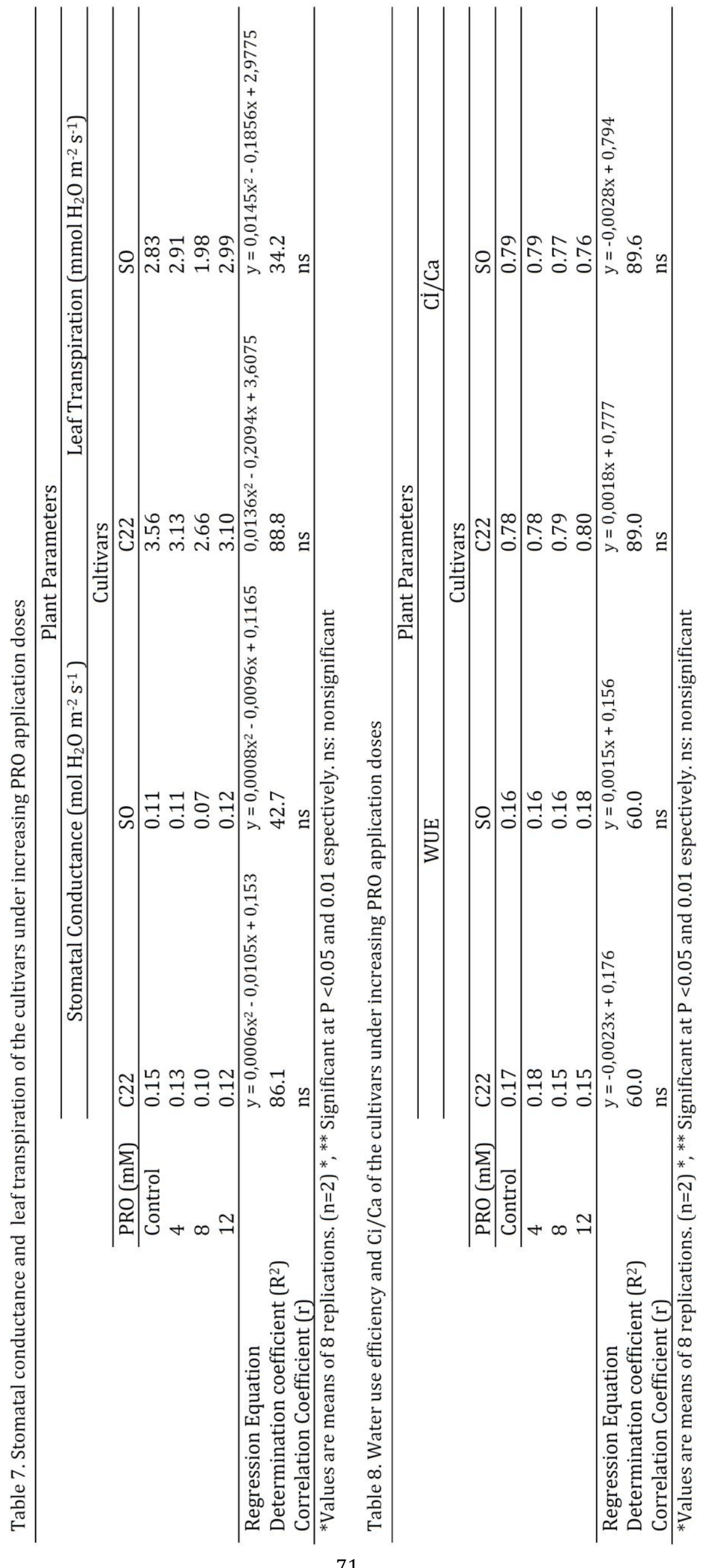


But it is clear that $\mathrm{Cl}$ does not contribute to the process (Table 1). Although there is a slight fluctuation in 8 mM PRO application dose, constant increase in PRO accumulation of the cultivar C22 leaves support this process (Table 3). Change in tendency of TPC in the cultivar C22 also seem to support this process (Table 4).

Cultivar SO exhibited different responses compared the C22 in terms of PRO and TPC accumulation in its leaves. Highest PRO accumulation value was found in the leaves of the control plants (Table 3). PRO accumulation dropped dramatically after the first application dose (4 mM PRO) and then increased constantly with the increasing doses. The greater accumulation of PRO in control plants' leaves of cultivar SO cultivar may result from high endogenous production under salinity. There are some inconsistent results about the probable reasons of PRO accumulation in plants under stress. According to Ramajulu and Sudhakar (2000) PRO accumulation is one of the results of the adaptation of plants to salinity. Some authors did not observe any appreciable increase in PRO content (Jain et al., 1987, Mousa, 2010) while others consider an enhanced PRO level merely as a stress effect (Moftah and Michel, 1987). It has been reported that PRO accumulation appears to be a reaction to salt-stress damage (de Lacerda et al., 2003) or a symptom of salt-susceptibility (Chen et al., 2007) and not a plant response associated with salt tolerance.

TPC accumulation of the SO cultivar was found nonsignificant with the lowest "determination coefficient $\left(\mathrm{R}^{2}\right)$ " value of the study which means that the related "regression equation" explaines only 9.2 percent of the change in the TPC accumulation under increasing PRO doses (Table 4). Many researchers stated that the synthesis and accumulation of phenolic compounds is generally stimulated in response to biotic and abiotic stresses in plants (Dixon and Paiva, 1995; Naczk and Shahidi, 2004). However different findings have also been published by other researchers. For instance, according to Ksouri et al. (2007) salinity reduced the TPC of Cakile maritima (cv Tabarka) leaves. The authors stated that relationship between salinity and TPC of the leaves is possibly related to the salinity tolerance level of the plants. As reported by Agastian et al. (2000) TPC and PRO contents of different mulberry genotypes increased at low salinity levels (1-2 $\left.\mathrm{dS} \mathrm{m}^{-1}\right)$ and decreased at high salinity levels (8-12 $\left.\mathrm{dS} \mathrm{m}^{-1}\right)$. Phenolic compounds belong to the category of natural antioxidants and their abundance is positively and directly related to the antioxidant capacity of plants (Boskou and Visioli, 2003). Therefore it may be concluded that increasing foliar PRO application doses contributed significantly to the osmotic adjustment in the cells of the plants.

According to Demiral et al. (2011) DPPH scavenging activity expressed as IC $_{50}$ was greatly affected by salinity and the scavenging activities of water extracts decreased at higher salinity levels. Although there are small differences, increasing PRO doses stimulated DPPH scavenging activity of the cultivars in the study. DPPH scavenging activity of cultivar C22 leaves fluctated while DPPH scavenging activity of cultivar SO leaves' decreased up to $8 \mathrm{mM}$ PRO application dose and then increased in the final dose (Table 4). It is known that a lower $\mathrm{IC}_{50}$ value reflects improved DPPH radical scavenging activity (Molyneux, 2004). Hence, it might be concluded that increasing PRO doses did not affect DPPH radical scavenging activity positively except the highest PRO dose (12 mM PRO) applied to the SO cultivar (Table 4).

RP of the cultivars increased steadily with the increasing foliar PRO application doses (Table 3). As reported by Demiral et al. (2011) increased salinity led to a general decrease in PR in olive plant. Hence it may be speculated that increasing PRO doses stimulated the production of metabolites responsible for the reducing mechanism of the plants under salt stress.

In terms of leaf water relation parameters (pressure, osmotic and water potentials); the cultivars showed similar responses to the increasing PRO doses. All the parameters changed direction in $8 \mathrm{mM}$ PRO application dose (Table 5, Table 6).

Increasing foliar PRO application doses clearly affected water potentials of the test plants' leaves (Table 6). As expected, increasing PRO doses affected pressure and water potentials in positive ways. This positive effect continued up to $8 \mathrm{mM}$ PRO dose and then changed direction, but the pressure potential of the cultivar C22 did not obey this tendency. This parameter was quite high in control plants, then decreased in the first application dose and increased constantly again (Table 5). If the pressure potential result of cultivar C22 is ignored, it can be said that PRO application contributed to water balance of the plant cells under salinity up to $8 \mathrm{mM}$ PRO level. These parameters decreased in the highest application dose (12 mM PRO). Osmotic potentials of the test plants also support this tendency. These results suggest that the conclusive effect of foliar PRO may be attributed to two factors; the toxicity of the PRO molecule itself and the stimulation of salt uptake. Exogenous PRO interfered with the normal process of osmotic adjustment based on the accumulation of ions such as $\mathrm{Na}$ and $\mathrm{Cl}$. Increasing PRO doses stimulated water absorption and/or hindered uptake of ions such as $\mathrm{Na}^{+}$and $\mathrm{Cl}^{-}$by the roots. 
A nonsignificant effect of foliar PRO application was observed on WUE of the cultivars (Table 8). However the cultivars differed in terms of $\mathrm{CI} / \mathrm{Ca}$. $\mathrm{CI} / \mathrm{Ca}$ of cultivar $\mathrm{C} 22$ decreased under increasing foliar PRO application (Table 8). Leaf transpiration, stomatal conductance and photosynthesis of the test plants' leaves showed more or less similar patterns between the cultivars. In all these parameters control plants gave slightly higher values than that of $4 \mathrm{mM}$ and $8 \mathrm{mM}$ PRO application doses. These results suggest that using of distilled water as control application decreased the stress level of the test plants under salt stress more than expected. Hence the effects of PRO applications on the test plants under salinity became uncertain.

A number of studies show that plant growth is positively associated with photosynthetic capacity, and decline in plant growth due to salt stress is often attibuted to suppression in photosynthesis (Lawlor, 2002; Jamil et al., 2007; Noreen et al., 2010). However, considerable salt-induced reduction in photosynthesis rate is attributed to reduced optimum concentration of photoassimilates required for better growth (Maas and Nieman, 1978), reduced leaf area (Marcelis and Hoojdonk, 1999), and inbalance in water status (Ashraf, 2004). According to da Silva Sa et al. (2016), exogenous application of PRO on the leaves reduced stomatal conductance and consequently affected the transpiration of bell pepper plants irrigated with water of low salinity (Table 7). It should be pointed out that the reduction in stomatal conductivity in plants under controlled application (distilled water) reached higher levels, compared to the plants treated with various PRO doses. These results denote the efficiency of exogenous application of PRO in the stomatal regulation of test plants, promoting higher transpiration without any damage to photosynthetic activity and with gains in water use efficiency (Table 6, Table 8).

These responses may be related to the osmotic adjustment promoted by the exogenous application of PRO on the leaves, so that transpiration guaranteed the occurrence of absorption and transport of water inside the plant, maintaining its water relationships active, through stomatal regulation. Thus, the increase in transportation is an indication of the efficiency of exogenous application of PRO in the osmotic regulation of the test plants, especially because there was an increase in the WUE of these plants.

Based on the results obtained in this experiment we conclude that foliar PRO application decreased $\mathrm{Na}, \mathrm{Cl}$ concentrations of the leaves and improved spesific leaf area in the final dose. Water leaf relations, photosynthetic activity and biochemical parameters were affected positively even though some differences were determined between the cultivars. However, more studies have to be carried out in near future to determine optimal concentrations of PRO that provide beneficial effects in citrus plant grown in different development stages.

\section{References}

Agastian, P., Kingsley, S.J., Vivekanandan, M., 2000. Effect of salinity on photosynthesis and biochemical characteristics in mulberry genotypes. Photosynthetica 38(2): 287-290.

Ashraf, M., 2004. Some important physiological selection criteria for salt tolerance in plants. Flora - Morphology, Distribution, Functional Ecology of Plants 199(5): 361-376.

Bates, S.L., Waldren, R.P., Teare, I.D., 1973. Rapid determination of free proline for water stress studies. Plant and Soil 39(1): 205-207.

Boskou, D., Visioli, F., 2003. Biophenols in table olives. In: Bioavailability of Micronutrients and Minor Dietary Compounds. Metabolic and Technical Aspects. Vaquero, M.P., Garcia-Arias, T., Garbajal, A. (Eds.). Research Signpost, Trivadrum, India. pp. 161-169.

Brand-Williams, W., Cuvelier, M.E., Berset, C., 1995. Use of a free radical method to evaluate antioxidant activity. $L W T$ Food Science and Technology 28(1): 25-30.

Brown, J.G., Jackson, R.K., 1955. A note on the potentiometric determination of chloride. Proceedings of the Society for Horticultural Science 65: 187-193.

Chen. Z., Cuin. T.A., Zhou, M., Twomey, A., Naidu, B.P., Shabala, S., 2007. Compatible solute accumulation and stressmitigating effects in barley genotypes contrasting in their salt tolerance. Journal of Experimental Botany 58(1516): 4245-4255.

da Silva Sá, F.V., de Lima, G.S., dos Santos, J. B., Gheyi, H.R., dos Anjos Soares, L.A., Cavalcante, L.F., de Paiva, E. P., de Pádua Souza, L., 2016. Growth and physiological aspects of bell pepper (Capsicum annuum) under saline stress and exogenous application of proline. African Journal of Biotechnology 15(36): 1970-1976.

de Lacerda, C.F., Cambraia, J., Oliva, M.A., Ruiz, H.A., Prisco, J.T., 2003. Solute accumulation and distribution during shoot and leaf development in two sorghum genotypes under salt stress. Environmental and Experimental Botany 49(2): 107-120.

Demiral, M.A., Aktas Uygun, D., Uygun, M., Kasırğa, E., Karagözler, A.A., 2011. Biochemical response of Olea europaea cv. Gemlik to short-term salt stress. Turkish Journal of Biology 35: 433-442.

Dixon, R.A., Paiva, N.L.,, 1995. Stress-induced phenylpropanoid metabolism. The Plant Cell 7(7): 1085-1097.

Flowers, T.J., Troke, P.F., Yeo, A.R., 1977. The mechanism of salt tolerance in halophytes. Annual Review of Plant Physiology 28: 89-121. 
Itai, C., Paleg L.G., 1982. Responses of water-stressed Hordeum distichum L. and Cucumis sativus to proline and betaine. Plant Science Letters 25(3): 329-335.

Jain, R.K., Dhawan, R.S., Sharma, D.R., Chowdhury, J.B., 1987. Salt-tolerance and proline accumulation: a comparative study in salt-tolerant and wild type cultured cells of eggplant. Plant Cell Reports 6(5): 382-384.

Jamil, M., ur Rehman, S., Lee, K.J., Kim, J.M., Hyun-Soon, K., Rha, E.S., 2007. Salinity reduced growth PSII photochemistry and chlorophyll content in radish. Scientia Agricola 64(2): 111-118.

Ksouri, R., Megdiche, W., Debez, A., Falleh, H., Grignon, C., Abdelly, C., 2007. Salinity effects on polyphenol content and antioxidant activities in leaves of the halophyte Cakile maritima. Plant Physiology and Biochemistry 45(3-4): 244249.

Lawlor, D.W., 2002. Limitation to photosynthesis in water-stressed leaves: stomata vs. metabolism and the role of ATP. Annals of Botany 89(7): 871-885.

Lin, C.C., Kao, C.H., 2001. Cell wall peroxidase against ferulic acid, lignin and NaCl-reduced root growth of rice seedlings. Journal of Plant Physiology 158(5): 667-671.

Little, T.M., Hills, F.J., 1978. Agricultural experimentation: design and analysis. John Wiley and Sons Inc. New York, USA, $350 \mathrm{p}$.

Maas, E.V., Nieman, R.H., 1978. Physiology of plant tolerance to salinity. In: Crop tolerance to suboptimal land conditions. Jung, G.A., (Ed.). Soil Science Society of America, Special Publication, Madison, USA. pp. 277-299.

Marcelis, L.F.M., Hooijdonk, J.V., 1999. Effect of salinity on growth, water use and nutrient use in radish (Raphanus sativus L.). Plant and Soil 215(1): 57-64.

Moftah, A.H., Michel, B.E., 1987. The effect of sodium chloride on solute potential and proline accumulation in soybean leaves. Plant Physiology 83(2): 238-240.

Molyneux, P., 2004. The use of the stable free radical diphenylpicrylhydrazyl (DPPH) for estimating antioxidant activity. Songklanakarin Journal of Science and Technology 26(2): 211-219.

Mousa, A.K., 2010. Growth and biochemical constituents of olives as influenced by irrigation with treated industrial wastewater. Journal of Plant Nutrition 33(1): 1-14.

Naczk, M., Shahidi, F., 2004. Extraction and analysis of phenolics in food. Journal of Chromatography A 1054(1-2): 95111.

Noreen, Z.; Ashraf, M.; Akram, N.A., 2010. Salt-induced regulation of some key antioxidant enzymes and physiobiochemical phenomena in five diverse cultivars of turnip (Brassica rapa L.). Journal of Agronomy and Crop Science 196(4): 273-285.

Oyaizu, M., 1986. Studies on products of browning reaction. Antioxidative activities of products of browning reaction prepared from glucosamine. The Japanese Journal of Nutrition and Dietetics 44(6): 307-315.

Ramajulu, S., Sudhakar, C., 2000. Proline metabolism during dehydration in two mulberry genotypes with contrasting drought tolerance. Journal of Plant Physiology 157(1): 81-85.

Rhodes, D., Hanson, A.D., 1993. Quarternary ammonium and tertiary sulfonium compounds in higher plants. Annual Review of Plant Physiology and Plant Molecular Biology 44: 357-384.

Scholander, P.F., Bradstreet, E.D., Hemmingsen, E.A., Hammel, H.T., 1965. Sap pressure in vascular plants. Science 148(3668): 339-346.

Singleton, V.L., Orthofer, R., Lamuela-Raventós, R.M., 1999. Analysis of total phenols and other oxidation substrates and antioxidants by means of folin-ciocalteu reagent. Methods in Enzymology 299: 152-178.

Tester, M., Davenport, R., 2003. Na+ tolerance and Na+ transport in higher plants. Annals of Botany 91(5): 503-527.

Westerman, R.L., 1990. Soil Testing and Plant Analysis. Soil Science Society of America (SSAA). Book Series, Vol. 3, Issue 3. SSSA Publications, Madison, Wisconsin, USA.784p. 